\title{
BIOMASS COMBUSTION WITH IN SITU CO2 CAPTURE BY CaO. II.: EXPERIMENTAL RESULTS
}

Mónica Alonso*, Nuria Rodríguez, Belén González, Borja Arias, Juan C. Abanades

Instituto Nacional del Carbón, INCAR-CSIC, Francisco Pintado Fe, 26 Oviedo 33011, Spain

*corresponding author: mac@incar.csic.es

KEYWORDS: $\mathrm{CO}_{2}$ capture, carbonation, biomass combustion, negative emissions, climate change

\begin{abstract}
Experiments to prove the concept of biomass combustion with in situ $\mathrm{CO}_{2}$ capture by $\mathrm{CaO}$ have been conducted in a $30 \mathrm{~kW}$ interconnected fluidized bed test facility. $\mathrm{CO}_{2}$ capture efficiency in a combustor-carbonator reactor was measured over a range of operating conditions, using three biomasses (olive pits, saw dust and pellets). Overall $\mathrm{CO}_{2}$ capture efficiencies higher than $80 \%$ were achieved with sufficiently high solids circulation rates of $\mathrm{CaO}$ and solids inventories in the combustor-carbonator. Emissions of $\mathrm{CO}$ and $\mathrm{CH}_{4}$ were detected during the experiments possibly due to pulse feeding and/or an inappropriate air/fuel mixture. The application of a simple reactor model for combining biomass combustion and $\mathrm{CO}_{2}$ capture allows an effectiveness factor of 0.74 to be derived for all the experiments. This could be valuable for scaling up purposes.
\end{abstract}

\section{Introduction}

This paper is part II of a set of two papers on biomass combustion with in situ $\mathrm{CO}_{2}$ capture by $\mathrm{CaO}^{1}$. As was mentioned in part I, biomass shares important similarities with fossil fuels, especially with coal, and the conversion technologies are also similar ${ }^{2}$. Fluidized bed combustors are used worldwide to combust biomass and the inherent advantages of 
fluidized beds make them an important option for other biomass thermal conversion routes ${ }^{3}$. The combustion temperature of biomass in fluidized beds should be kept below $900{ }^{\circ} \mathrm{C}$ (normally inside the range of $\left.800-900{ }^{\circ} \mathrm{C}\right)^{4}$ to prevent the ash from sintering, as this could cause de-fluidization in the bed ${ }^{4}$. As a result of the combustion process, different types of emissions ${ }^{5}$ can be expected. These include: unburnt pollutants $\left(\mathrm{CO}, \mathrm{C}_{\mathrm{x}} \mathrm{H}_{\mathrm{y}}, \operatorname{tar}, \mathrm{PAH}\right.$, soot, unburnt carbon, $\mathrm{H}_{2}, \mathrm{HCN}, \mathrm{NH}_{3}$ and $\left.\mathrm{N}_{2} \mathrm{O}\right)$, pollutants from complete combustion $\left(\mathrm{CO}_{2}, \mathrm{NO}_{\mathrm{x}}\right.$, and $\mathrm{H}_{2} \mathrm{O}$ ), and ash and contaminants such as particles, $\mathrm{SO}_{2}, \mathrm{HCl}, \mathrm{Cu}, \mathrm{Pb}, \mathrm{Zn}$, etc... In order to prevent unburnt pollutants from being emitted, the combustion air and fuels (i.e. char and volatiles) should be properly mixed. In addition a high combustion temperature and sufficient residence time in the hot, oxidizing zone ${ }^{6}$ should be employed. The pollutants originated by combustion are critically related with the properties of the biomass ${ }^{6}$, but one of the main characteristics of the system proposed in part I is that the biomass combustion with "in situ" $\mathrm{CO}_{2}$ capture takes place at a lower temperature than is normally the case (around $700^{\circ} \mathrm{C}$ ). This mode of operation is very uncommon in combustors ${ }^{2}$, and the authors have only found one reference to this by Muthukrihnan et al. ${ }^{7}$, who reported the combustion of $100 \%$ rice stalk in a $10 \mathrm{MW}$ fluidized bed combustion plant at a bed temperature of $600{ }^{\circ} \mathrm{C}$ and a freeboard temperature of $720{ }^{\circ} \mathrm{C}$. The main problems reported were related with fouling and slagging. The high volatiles contents and the fact that biomass was fed over the bed led to significant freeboard combustion. This resulted in high flue gas temperatures that caused the ash (which had a high alkaline content) to soften and to settle on the tubes of the superheater. 
Among the processes that are under development and that are similar to the process described here is the AER (Absorption Enhanced Reforming) process which uses lime as a sorbent for $\mathrm{CO}_{2}$ capture during biomass gasification ${ }^{8-10}$. For in situ $\mathrm{CO}_{2}$ capture during the steam gasification of biomass, a comprehensive review of state of the art knowledge has been published by Florin and Harris ${ }^{11}$.

The main goal of this work is to investigate the combustion of biomass and $\mathrm{CO}_{2}$ capture efficiency in a combustor-carbonator in experimental tests using a laboratory scale CFBC, operating at appropriate combustion temperatures to allow the capture of $\mathrm{CO}_{2}$ by $\mathrm{CaO}$.

\section{Experimental}

The experimental test rig consists of two interconnected circulating fluidized bed reactors. A diagram of the installation is shown in Figure 1. The combustor-carbonator and the combustor-calciner have heights of $6.3 \mathrm{~m}$ and $6.1 \mathrm{~m}$ respectively. The internal diameter of both reactors is $0.1 \mathrm{~m}$. No air distributors are used in order to facilitate the feed of biomass or other fuels to the reactors. This is achieved by using screw feeders fitted to the cold air entrances to the reactors. The bottom $3 \mathrm{~m}$ of each riser is surrounded by electrical ovens which are independently controlled, the remaining top part of each riser and the rest of the primary circulation loop are thermally insulated. Each riser is connected to a high efficiency primary cyclone where the solids are separated from the gas phase. The solids fall from the cyclones into a loop seal through a standpipe. The loop seals are fluidized with air. The solids flow over the seals into the other riser through an inclined standpipe. At this point they have completed half of the solids circulating loop. In the inclined standpipe 
leading to the combustor-carbonator there is a bypass just below the loop seal for extracting solid samples and for measuring the solids circulation rates (Gs, in $\mathrm{kg} / \mathrm{m}^{2} \mathrm{~s}$ ). This is achieved by diverting the solids to a dead volume between two valves for a certain period of time. On leaving the primary cyclones the gases go to the secondary cyclones in order to improve the gas-solid separation before being expelled through the exhaust. Solids from secondary cyclones are returned to the primary loop in periodic batches to compensate for the loss of solids in the primary cyclones (97-99\% solids capture efficiency).

The pilot rig is fitted with 40 thermocouples, 16 of which are positioned in the risers. There are 20 differential pressure taps and 4 oxygen zirconia probes, of which three are in the combustor-carbonator and one is in the combustor-calciner.

Gas concentration measurements $\left(\mathrm{CO}, \mathrm{CO}_{2}, \mathrm{O}_{2}\right.$ and $\left.\mathrm{CH}_{4}\right)$ are continuously performed by two on-line gas analyzers. There are several points in the installation where it is possible to extract the gas for analysis, but usually this is done at the gas exits of the secondary cyclones because at these points the gas contains low loads of solids. The oxygen zirconia probes are used to follow the quality of combustion. The oxygen probes in the combustorcarbonator are located at a height of $0.5 \mathrm{~m}, 3 \mathrm{~m}$ and $6.3 \mathrm{~m}$ above the air entrance. There is another probe $3 \mathrm{~m}$ above the air entrance in the combustor-calciner. As the oxygen probes measure the local and instant oxygen concentrations in the vicinity of the probes, the bottom probe in the combustor-carbonator is used to check for reduction conditions in the bed, as will be explained below. The other oxygen probes are used to increase the reliability of the $\mathrm{O}_{2}$ composition measurements made by the on-line gas analyzers and to gauge the 
gas split in the loop-seal. Since aeration in the loop-seal can amount to as much as $20 \%$ $30 \%$ of the total flow of gas entering the riser and there is a certain degree of uncertainty as to the path this aeration takes, the average of the oxygen concentration measured by the probe is used to estimate the fraction of aeration that goes to the riser and the fraction that goes to the primary cyclone. In normal circulation conditions, with a good solids seal in the loop-seal, all the gas that enters the loop seal goes to the riser, so the average oxygen concentration measured by the probe should be equal to the oxygen concentration measured by the analyzer. However, when the solids circulation flow rate is low, a fraction of the air fed into the loop seal goes to the cyclone. The average oxygen concentration measured by the zirconia probes is then slightly smaller than the oxygen concentration measured by the analyzer. Thus it is possible to estimate the air flow to the cyclone by using the $\mathrm{O}_{2}$ concentration measured by the on-line gas analyzer and the zirconia oxygen probe at the riser exit. This estimation is done by taking the average of the signal during around half hour and compares it with the average of the $\mathrm{O}_{2}$ concentration measure by the analyzer during the same period of time.

Samples of solids (20-50 g) are taken from the combustor-carbonator, combustor-calciner and from the loop seal of the combustor-carbonator by opening ports located at different points. These samples are analyzed for total calcium oxide content, calcium carbonate and maximum calcium conversion to carbonate (the maximum absorption capacity of $\mathrm{CO}_{2}$, in a TGA test operating at $650{ }^{\circ} \mathrm{C}$, and $10 \%$ vol. of $\mathrm{CO}_{2}$ over a 10 min reaction time). Some of these samples are selected for more detailed chemical or textural analysis. 
Two different Spanish limestones were used during the experiments, both of which had an initial particle diameter of 180 and $130 \mu \mathrm{m}$. However, the solids experienced intense attrition and they reached an average particle diameter of 100 and $70 \mu \mathrm{m}$ respectively after 10 hours of operation as described in more detailed elsewhere ${ }^{12}$.

Three types of biomass were used in the experiments: sawdust, crushed olive pits and commercial wood pellets (pine sawdust). The proximate and ultimate analyses as well as the heating values are shown in Table 1 . These analyses correspond to the average values of the biomass fed into the combustor-carbonator. The sawdust was sieved to a particle size of less than $4 \mathrm{~mm}$ and pre-dried before use (densification techniques were not used), the wood pellets used was crushed and sieved to a particle size less than $4 \mathrm{~mm}$ too. The moisture content of the biomass was kept below $15 \%$. This will affect the quality of combustion ${ }^{13}$ at low temperatures. There are no changes attributed to the used of different sorbents and fuels.

The experiment commences with the calcination of a batch of limestone or solids from previous experiments, normally around $20 \mathrm{~kg}$, which is loaded into the loop seals and risers. Calcination is carried out by burning either biomass or coal in the combustor-calciner and biomass in the combustor-carbonator in air-fired combustion conditions. In calcination conditions, all the electrical ovens are switched on, at ignition temperatures between 500 and $550{ }^{\circ} \mathrm{C}$. At this point the maximum fuel flows are used (about $20 \mathrm{~m}^{3} \mathrm{~N} / \mathrm{h}$ and $3 \mathrm{~kg}$ fuel/h) with an $\mathrm{O}_{2}$ content in the flue gas between 3-5\% vol. Temperatures during calcination are around $800{ }^{\circ} \mathrm{C}$ at the bottom of the risers. Rapid temperature excursions (up to $1000{ }^{\circ} \mathrm{C}$ ) 
may occur if the solids circulation rate is interrupted or if total calcination of the batch is achieved due to the impact of the partially carbonated solids on the heat balance in the calciner ${ }^{14}$. As discussed in part I, the application of this technology in the future will involve the recovery of a pure stream of $\mathrm{CO}_{2}$ from the decomposition of $\mathrm{CaCO}_{3}$ by oxygen/carbon dioxide calcination under CFB conditions. However, no differences in the performance of the key sorbent parameters are expected as long as the calcination temperature remains below $950^{\circ} \mathrm{C}{ }^{15}$. After the calcination of the batch is completed (i.e. when the carbonate content in the solids samples is $<5 \%$ ), the electrical ovens in the combustor-carbonator are switched off in order to allow the temperatures to decrease towards $650-700{ }^{\circ} \mathrm{C}$, where both the combustion and carbonation reactions take place.

\section{Results and Discussion}

The experimental installation in Figure 1 was designed to operate for long periods of time in continuous and stable mode, with the occasional reinjection of solids into the primary circulation loop in order to compensate for the natural loss of solids in the primary cyclones. Unfortunately, most of our early experimental results from biomass-combustion tests were obtained in non steady state as described elsewhere ${ }^{16}$. The objective of this work is to report the results of new experiments performed in much more stable conditions, although some valuable information has also been obtained from some non-stationary periods, as will be discussed below.

The operational range of the main conditions is shown in Table 2. As pointed out before, the bed temperatures in the combustor-carbonator should be in the range of $650-700{ }^{\circ} \mathrm{C}$ in 
order to maximize biomass combustion and $\mathrm{CO}_{2}$ capture, although in some cases the combustion efficiencies in the combustor-carbonator have been lower (down to $97 \%$ at $650^{\circ} \mathrm{C}$ and $3 \% \mathrm{O}_{2}$ excess). The superficial gas velocities were in the range of $1.5-2.4 \mathrm{~m} / \mathrm{s}$, since this is necessary to maintain the bed inventory in the riser and to ensure sufficient residence time for the fuel and an adequate combustion. The $\mathrm{CO}_{2}$ concentration from combustion that can be expected if no $\mathrm{CO}_{2}$ capture takes place varied between 7.3-15.9\% vol. which is the normal range for the combustion process. In our experiments solids circulating flow rates varied between 0.6 and $3.5 \mathrm{~kg} / \mathrm{m}^{2} \mathrm{~s}$, whereas the solids bed inventories varied between $45 \mathrm{~kg} / \mathrm{m}^{2}$ and $650 \mathrm{~kg} / \mathrm{m}^{2}$.

In order to facilitate the presentation and discussion of the experimental results, the raw experimental gas concentration measurements have been transformed into instant $\mathrm{CO}_{2}$ capture efficiencies which are defined as:

$\mathrm{CO}_{2}$ capture efficiency $=\frac{\mathrm{F}_{\mathrm{CO} 2 \text { comb }}-\mathrm{F}_{\mathrm{CO} 2 \text { out }}}{\mathrm{F}_{\mathrm{CO} 2 \text { comb }}}$

where $\mathrm{F}_{\mathrm{CO} 2 \mathrm{comb}}$ is the total flow rate of $\mathrm{CO}_{2}$ generated from combustion in the reactor, that is estimated from an oxygen balance as discussed elsewhere ${ }^{16}$, using the continuous measurement of $\mathrm{O}_{2}$ at the exit of the combustor-carbonator, the flow rate of air trough risers and loop seals and the elemental analysis of the fuel fed to the reactor.

Figures 2 to 4 show examples of the experimental results, some of which correspond to experimental intervals where there is still a certain non-stationary state affecting key 
variables that determine reactor performance. In contrast Figure 3 shows a typical stationary state interval corresponding to about $14 \mathrm{~h}$ of continuous and trouble-free operation. However both types of experiments, both stationary and non-stationary state, are useful for extracting valuable information, as will be discussed in the following paragraphs.

Figure 2 presents the experimental results corresponding to the beginning of in situ $\mathrm{CO}_{2}$ capture. Figure 2 (a) shows the combustor-carbonator bed temperature (grey line) and the solids inventory in the combustor-carbonator riser (black line). During this period, the bed temperature dropped from temperatures of around $850^{\circ} \mathrm{C}$ to temperatures of around $710^{\circ} \mathrm{C}$ as this period corresponds to the time after the ovens have been switched off in order to lower the temperatures and initiate $\mathrm{CO}_{2}$ capture. The bed inventory during calcination was around $200 \mathrm{~kg} / \mathrm{m}^{2}$. However, at 14:07 $\mathrm{h}$ a batch of solids was fed into the combustorcalciner loop-seal, and the bed inventory in the combustor-carbonator consequently rose to $380 \mathrm{~kg} / \mathrm{m}^{2}$, remaining at around $350 \mathrm{~kg} / \mathrm{m}^{2}$ in steady-state. At the end of this period, the solids circulating flow rate was estimated to be around $1.8 \mathrm{~kg} / \mathrm{m}^{2} \mathrm{~s}$. Figure $2(\mathrm{~b})$ shows the $\mathrm{O}_{2}$ and $\mathrm{CO}_{2}$ concentrations at the exit of the primary loop, as measured by the gas analyser. The $\mathrm{CO}_{2}$ combustion concentration as estimated, from the oxygen concentration measurements varied between 13.8 and $16.3 \%$ vol, whereas the $\mathrm{CO}_{2}$ concentration measured at the exit of the combustor-carbonator dropped from $15 \%$ vol. (during calcination) to $5 \%$ vol when the temperature was around $710^{\circ} \mathrm{C}$ due to the carbonation of the $\mathrm{CaO}$ in the bed. Figure 2(c) shows the instant capture efficiency (black) and the maximum capture efficiency allowed by the equilibrium (grey) during this period. As the combustor-carbonator temperature decreased from calcination temperatures to temperatures 
close to $700{ }^{\circ} \mathrm{C}$, both the equilibrium efficiency and experimental efficiency increased. Moreover, both efficiencies approached the same average value of $80 \%$ towards the end of this period. This is an indication in itself of good reactor performance when a sufficiently large flow of active $\mathrm{CaO}$ is fed into the combustor-carbonator and a sufficient inventory of material is present in the reactor. In Figure 2, the conditions are such that at many experimental points, experimental capture efficiency seems to be slightly above the maximum allowed by equilibrium. This is due to the choice of the temperature used to estimate the $\mathrm{CO}_{2}$ partial pressure at equilibrium. The temperature always used is the average temperature of the dense bed. However at the start this temperature was slightly higher than the temperature at the exit of the combustor-carbonator, where more $\mathrm{CO}_{2}$ capture is allowed.

Figure 3 shows an example of "in situ" $\mathrm{CO}_{2}$ capture in steady-state conditions. During this period, the bed temperature varied between $675^{\circ} \mathrm{C}$ and $710^{\circ} \mathrm{C}$ (Figure 3(a) grey line) while the bed inventory varied between $500 \mathrm{~kg} / \mathrm{m}^{2}$ and $400 \mathrm{~kg} / \mathrm{m}^{2}$ (Figure 3(a) black line). The circulation flow rate in this period was found to be at around $1 \mathrm{~kg} / \mathrm{m}^{2} \mathrm{~s}$ and the maximum carbonation conversion of solids extracted from the reactors was 0.3 . The average capture efficiency was estimated to be $81 \%$ (Figure 3(b)) while the maximum capture efficiency allowed by the equilibrium at this temperature was $82 \%$.

Figure 4 shows how the system reacts when the solids inventory is changed. During this period, the bed temperature (Figure 4(a) grey line) was observed to oscillate at around 650 ${ }^{\circ} \mathrm{C}$ except between 18:52-18:57 when a minimum of around $525^{\circ} \mathrm{C}$ was reached due to a 
problem in the biomass feeding system. At the beginning of the period, (Figure 4 (a) black line), the solids inventory was around $140 \mathrm{~kg} / \mathrm{m}^{2}$ subsequently decreasing to values of around $60 \mathrm{~kg} / \mathrm{m}^{2}$. At this point a plug in the biomass feeding was detected due to an abrupt increase in the pressure drop, as a result of which biomass feeding had to be interrupted. Due to the system being cut off, solids from the calciner accumulated in the combustorcarbonator. When the system was re-started, the solids inventory was around $150 \mathrm{~kg} / \mathrm{m}^{2}$, subsequently decreased to values of around $70 \mathrm{~kg} / \mathrm{m}^{2}$. The solids circulation flow rate was measured twice during this period: at the beginning when it was $1.7 \mathrm{~kg} / \mathrm{m}^{2} \mathrm{~s}$ and at the end when it was $0.8 \mathrm{~kg} / \mathrm{m}^{2}$ s. Capture efficiency reached values of around $81 \%$ at the beginning of the period (Figure 4 (b) black dots), the maximum capture efficiency allowed by equilibrium being around 95\% (grey dots). As the bed inventories decreased, the capture efficiencies also decreased, to an average value of $50 \%$ just before the cut-off. After the accumulation of solids in the carbonator, before 19:00, $\mathrm{CO}_{2}$ capture efficiency increased again to values above $90 \%$ although, when the bed inventories reached values of around 70 $\mathrm{kg} / \mathrm{m}^{2}$ the capture efficiency decreased to values close to those prior to shut off. These results again show the importance of having a sufficient inventory of active $\mathrm{CaO}$ in the combustor-carbonator to ensure the necessary gas and solids residence times for achieving high capture efficiencies.

Due to the low temperatures of combustion, a cause for concern in all the experiments reported in this work was the emission of $\mathrm{CO}$ and $\mathrm{CH}_{4}$ (as measured by the on-line gas analyzer) from the combustor-carbonator. $\mathrm{CO}$ and $\mathrm{CH}_{4}$ emissions during biomass combustion are attributed to a poor combustion quality usually for one or more of the 
following reasons: a low combustion temperature, an insufficient mixing of fuel with combustion air and insufficient residence time of the combustible gases in the combustion zone $^{2}$. Figure 5 shows an example of the experimental concentrations of the main gases measured during an experiment in which the biomass consisted of wood pellets. The $\mathrm{O}_{2}$ concentration was measured by means of a zirconia probe installed $0.5 \mathrm{~m}$ above the feed point in the combustor-carbonator and the $\mathrm{CO}$ and $\mathrm{CH}_{4}$ concentrations were determined at the exit of the primary loop. During this period $\mathrm{CO}_{2}$ capture efficiency was estimated to be between $70 \%$ and $80 \%$, whereas the $\mathrm{CO}_{2}$ coming from combustion without any $\mathrm{CO}_{2}$ having been captured was estimated to be around $14 \%$. As can be seen from Figure 5, the probe detected rapid variations in the oxygen concentration between the reduction and oxidation conditions, even when at the exit of the primary loop, the on-line gas analyzer detected a stable $\mathrm{O}_{2}$ concentration with a minimum of $2.9 \%$ of $\mathrm{O}_{2}$ (not shown in the Figure for clarity). As can be seen in Figure 5 the reduction conditions, as detected by the oxygen probe possibly lasted for as long as 1 min. Moreover, the $\mathrm{CO}$ and $\mathrm{CH}_{4}$ gas concentration peaks correlate perfectly with each other, whereas the CO concentration base line is 450 ppm and that of $\mathrm{CH}_{4}$ is $600 \mathrm{ppm}$. However, both concentrations increased by as much as $1 \%$ and $1.7 \%$ respectively over short periods of time. These high concentrations are clearly related with the oxygen depleted conditions detected by the zirconia probe located $0.5 \mathrm{~m}$ above the feed point. It is well known ${ }^{2,4,17}$ that the large generation of volatiles from biomass particles fed into a fluidized bed can give rise to alternating oxidizing and reducing conditions at different locations in the bed. Although this complex phenomenon may partially explain our findings, the periodic nature of the oscillations in the $\mathrm{O}_{2}$ concentration measured by the zirconia probe suggests that the cause of these oscillations was more trivial in our case, and very much related with the oscillations with time inherent in our small 
biomass feeding system (i.e. the screw feeder discharging biomass into an inclined pipe which at the same time is feeding air into the reactor).

As pointed out in the Experimental section, a mass balance using the $\mathrm{O}_{2}$, and $\mathrm{CO}_{2}$ concentrations measured by the on-line gas analyzer at the exit of the primary loop, together with the composition of the biomass feed, allows the biomass feed rate to be estimated. Figure 6 presents the results for a specific period of time of an experiment. The black line corresponds to the calibration of the screw feeder $(2.31 \mathrm{~kg} / \mathrm{h})$, while the dark grey line corresponds to the feed rate calculated on the basis of the difference in oxygen contents at the inlet and the outlet of the combustor-carbonator and the biomass composition. As can be seen, the estimated biomass feed rate varies between 1.6 and 2.9 $\mathrm{kg} / \mathrm{h}$, the average being $2.2 \mathrm{~kg} / \mathrm{h}$ which is very close to the value calibrated. The oscillations, which are quite large, are thought to be associated with the feeding of biomass into the bed in pulses. Although the screw feeder displays a more stable fuel feeding during calibration, it is clear that the biomass enters the reactor in small batches, causing oscillations in $\mathrm{O}_{2}$ concentration in the vicinity of the zirconia probe. Optimization of the feeding system and the air staging conditions is beyond the scope of this small scale facility, but on a large scale these emissions must be taken into consideration when designing the biomass feeding system.

Mass balances were performed to check whether they fit and the reliability of the different sources of experimental data. Furthermore an approximation to a simple biomass combustion model was made in order to estimate the average overall effectiveness factor 
for this test facility. Even with the application of a simple model the results should be useful in designing future pilot plants and for assessing the performance of combustorcarbonator reactors at a large scale.

Since the gas balance in the system establishes itself in the few seconds that the gas takes to pass through the risers, it is possible to measure all the experimental data to check the following mass balance:

$\mathrm{F}_{\mathrm{CO} 2 \text { comb }} \cdot \mathrm{E}_{\text {carb }}=\frac{\mathrm{Gs}}{\mathrm{PM}_{\text {calc }}} \cdot \Delta \mathrm{X}$

where $\mathrm{E}_{\mathrm{carb}}$ is the capture efficiency, $\mathrm{F}_{\mathrm{CO} 2 \mathrm{comb}}$ the $\mathrm{CO}_{2}$ molar flow rate generated by combustion, $\mathrm{kmol} / \mathrm{m}^{2} \mathrm{~s}$, Gs the solid circulating flow rate, $\mathrm{kg} / \mathrm{m}^{2} \mathrm{~s}, \mathrm{PM}_{\text {calc }}$ the molecular weight of the solids that enter the combustor-carbonator, $\mathrm{kg} / \mathrm{kmol}$, and $\Delta \mathrm{X}$ the difference between the carbonate contents of the samples in the combustor-carbonator and the combustor-calciner.

Figure 7 (a) presents a comparison of all the experimental data. If all measurements are precise and provided there was no accumulation in the bed, all the experimental points should be on the diagonal. As can be seen the closure of the mass balance is reasonable. As previously mentioned, most of the experimental data were obtained in non-steady state conditions from a solids point of view. The samples where the gas phase was also in non 
steady-state conditions (i.e. at the time when the solids samples were taken, capture efficiency varied more than $10 \%$ ) have been rejected.

To estimate the average overall effectiveness factor the carbonation reactions of $\mathrm{CaO}$ must first be discussed. Bathia and Perlmutter ${ }^{18}$ were the first to investigate in detail the reactivity of $\mathrm{CaO}$ over $\mathrm{CO}_{2}$. They referred to previous works that had agreed on a very rapid drop in reaction rate after a given value of conversion. Only the fast reaction period is relevant for the process described in this work. We recently extended ${ }^{19}$ the model introduced by Bathia and Perlmutter to particles that had experienced a certain number of carbonation and calcination cycles and concluded that for highly cycled particles and modest particle residence times (like those in our experiments) a simpler kinetic model that accounts for the fast reaction rate of the fraction of active material in the bed at any given time may be sufficient for initial modelling purposes. In line with previous reactor models for the carbonation of a batch of $\mathrm{CaO}^{20}$ or for a post combustion reactor ${ }^{21}$, we assume here that the bed contains three types of sorbent particles: a fraction of active $\mathrm{CaO}$ reacting in the fast reaction regime $\left(\mathrm{X}_{\text {active }}\right)$, a fraction of inactive $\mathrm{CaO}$ from previous carbonationcalcination cycles, and a fraction of $\mathrm{CaCO}_{3}$ produced by the carbonation conversion $\left(\mathrm{X}_{\text {carb }}\right)$. Thus:

$$
\mathrm{X}_{\mathrm{active}}=\mathrm{X}_{\max }-\mathrm{X}_{\mathrm{carb}}
$$

where $\mathrm{X}_{\max }$ is the maximum carbonation achieved by the samples of solids at the end of the fast carbonation period in a standard TG carbonation test ${ }^{22,23}$ and $\mathrm{X}_{\text {carb }}$ is the carbonation 
conversion of the sample recorded for each experiment. The value of $\mathrm{X}_{\text {active }}$ is a function of the residence time of the particles in the combustor-carbonator circulating fluidized bed reactor and of their average reactivity material ${ }^{21}$. Therefore, the active $\mathrm{CaO}$ fraction must be linked to the bed inventory present in the CFB and to the decay in activity of the solids. This link that $\mathrm{X}_{\text {active }}$ has with the bed inventory requires that the fluid dynamic model of the entire interconnected system be solved ${ }^{24}$ in order to find a suitable solution. However, a continuous recording of the pressure drop in the solids bed and the extraction of samples from the bed during the experiments, allow the bed inventories and $\mathrm{X}_{\max }$ and $\mathrm{X}_{\text {carb }}$ in equation 3 to be estimated by simply determining the carbonate content of the samples and their fully carbonated equivalents.

The carbonation reaction rate of a representative particle of $\mathrm{CaO}$ can be expressed for low levels of conversion or for a flat surface of reacting $\mathrm{CaO}$ in the interior of the particles as:

$$
\frac{\mathrm{dX}}{\mathrm{dt}}=\frac{\mathrm{X}_{\mathrm{active}} \mathrm{k}_{\text {reac }}}{\mathrm{P}}\left(\mathrm{P}_{\mathrm{CO} 2}-\mathrm{P}_{\mathrm{CO} 2, \mathrm{eq}}\right)
$$

where $\mathrm{k}_{\text {reac }}$ is the reaction rate constant of the active part of the $\mathrm{CaO}$ in the bed, which is estimated to be around $0.37 \mathrm{~s}^{-1}$ from independent experiments with thermogravimetric equipment and reported by Grasa et al. ${ }^{22}$. On the basis of equation 4 , the mass balance between the gas phase and the solids in the bed could be written as:

$\mathrm{F}_{\mathrm{CO} 2 \text {, comb }} \mathrm{E}_{\text {carb }}=\varphi \mathrm{N}_{\mathrm{CaO}} \mathrm{X}_{\text {active }} \mathrm{k}_{\text {reac }} \frac{\left(\overline{\mathrm{P}}_{\mathrm{CO} 2}-\mathrm{P}_{\mathrm{CO} 2, \mathrm{eq}}\right)}{\mathrm{P}}$

where $\varphi$ is the overall effectiveness factor when there are resistances other than the reactions, $\overline{\mathrm{P}}_{\mathrm{CO} 2}$, is the $\mathrm{CO}_{2}$ mean partial pressure over the bed (atm), and $\mathrm{N}_{\mathrm{CaO}}$ is the total 
quantity of $\mathrm{CaO}$ moles present in the bed. In order to estimate the $\mathrm{CO}_{2}$ mean partial pressure in the bed it is necessary to assume a model for combustion. The basic model used assumes an overall reaction process where the combustion and carbonation reactions are in series, as follows:

Biomass $+\mathrm{O}_{2}+\mathrm{CaO} \stackrel{k_{\mathrm{comb}}}{\longrightarrow} \mathrm{CO}_{2}+\mathrm{CaO} \stackrel{{ }_{\text {carb }}}{\longrightarrow} \mathrm{CaCO}_{3}$

Assuming a combustion model for the first term of equation (6), it is possible to obtain the $\mathrm{CO}_{2}$ generation rate for any given atmosphere in the reactor. As was pointed out before, in this work the combustion submodel has been simplified by assuming that all the gases are in plug flow, all the solids are instantly mixed and the $\mathrm{O}_{2}$ partial pressure in the solids bed decays exponentially with the solids bed height between the air input value $\left(\mathrm{P}_{\mathrm{O} \text { in }}=0.21\right)$ and the output value measured at the exit of the reactor (experimental $\left.\mathrm{P}_{\mathrm{O} \text { exit }}\right)$. The final equation for the $\mathrm{CO}_{2}$ mean partial pressure over the bed is as follows, as a more detailed description is given elsewhere ${ }^{16}$.

$\overline{\mathrm{P}}_{\mathrm{CO} 2}=\frac{\mathrm{u}}{\mathrm{h}} \frac{\alpha \mathrm{P}_{\mathrm{O} 2, \text { in }}}{\left(\mathrm{k}_{\text {carb }}-\mathrm{k}_{\text {comb }}\right)}\left[\left(1-\mathrm{e}^{-\mathrm{k}_{\text {comb }} \frac{\mathrm{h}}{\mathrm{u}}}\right)-\frac{\mathrm{k}_{\text {comb }}}{\mathrm{k}_{\text {carb }}}\left(1-\mathrm{e}^{-\mathrm{k}_{\text {carb }} \frac{\mathrm{h}}{\mathrm{u}}}\right)\right]$

Thus, the model is fully defined by equation 5 and by substituting experimental information for $\mathrm{X}_{\text {active }}$ (equation 3), the bed inventory (assuming the bed to be formed only by $\mathrm{CaO}$ and $\mathrm{CaCO}_{3}$ particles), estimating $\mathrm{h}$ from the pressure drop measurements and $\overline{\mathrm{P}}_{\mathrm{CO} 2}$ by means of equation 7. Under these conditions, experimental measurements of $\mathrm{CO}_{2}$ capture in the gas 
phase (in mol $\mathrm{CO}_{2} / \mathrm{m}^{2} \mathrm{~s}$ ) can be compared directly with the results obtained by applying the model. This comparison is plotted in Figure 7 (b).

As can be seen in this Figure there is considerable scattering when the model predictions are compared with the experimental results, which is understandable in view of the gross simplifications adopted to build the model and the inherent uncertainties, especially in relation with the determination of $\mathrm{X}_{\max }$.

Despite the difficulties mentioned above, the overall trend for both the model predictions and experiments is reasonably similar with an effectiveness factor of 0.74 . This seems to indicate that the carbonation rate of reaction is indeed the controlling step of the overall process of combustion and $\mathrm{CO}_{2}$ capture. It also indicates that the rate of carbonation is sufficiently fast to achieve high capture rates of $\mathrm{CO}_{2}$ in beds formed by $\mathrm{CaO}$ particles with a certain active fraction reacting in the "fast carbonation regime". This simple model may be important for future design and scaling up exercises.

\section{Conclusions}

The concept of in situ $\mathrm{CO}_{2}$ capture during low temperature biomass combustion seems experimentally feasible when operating in a narrow temperature window of around $700^{\circ} \mathrm{C}$ to maximize both combustion and $\mathrm{CO}_{2}$ capture efficiencies in circulating fluidized beds fed with a continuous supply of $\mathrm{CaO}$ from a calciner. Experiments carried out at a continuous laboratory scale test facility have highlighted the need to guarantee a steady biomass feed to the combustor-carbonator in order to achieve a good quality of combustion while 
minimizing other minor emissions such as $\mathrm{CO}$ and $\mathrm{CH}_{4}$. A high sorbent solids inventory in the combustor-carbonator reactor, as well as an intense circulation of solids between this reactor and the calciner led to $\mathrm{CO}_{2}$ capture efficiencies over $80 \%$. Gas phase measurements were validated using samples of solids taken from reactors by means of mass balances. An initial model of the combustion-carbonation process and its validation against experimental data reveals that the overall process is controlled by the carbonation reaction rate of the active part of the $\mathrm{CaO}$ present in the bed. In summary, despite the small scale of the test facility, and the limitations of the experimental technique employed, the concept of capturing $\mathrm{CO}_{2}$ from biomass combustion with $\mathrm{CaO}$ "in situ" inside a fluidized bed combustion chamber has been demonstrated to be technically feasible. Further research is needed in order to extend the operational range to include conditions that resemble those found at industrial scale.

\section{Acknowledgments}

This work has been carried out thanks to the financial support from Gas Natural Fenosa, under the MENOS-CO2 project. M. Alonso, N. Rodriguez and B. Gonzalez also acknowledge the grants received through the JAE-Doc Programme from CSIC and FICYT. 


\section{Nomenclature}

\begin{tabular}{|c|c|}
\hline $\mathrm{E}_{\text {carb }}$ & $\mathrm{CO}_{2}$ capture efficiency \\
\hline $\mathrm{F}_{\mathrm{CO} 2 \mathrm{comb}}$ & $\mathrm{CO}_{2}$ molar flow rate coming from combustion, $\mathrm{kmol} / \mathrm{m}^{2} \mathrm{~s}$ \\
\hline $\mathrm{F}_{\mathrm{CO} 2 \text { out }}$ & $\mathrm{CO}_{2}$ molar flow rate at the exit of combustor-carbonator, $\mathrm{kmol} / \mathrm{m}^{2} \mathrm{~s}$ \\
\hline Gs & Solids circulation flow rate, $\mathrm{kg} / \mathrm{m}^{2} \mathrm{~s}$ \\
\hline $\mathrm{h}$ & Reactor length, m \\
\hline $\mathrm{k}_{\mathrm{carb}}$ & Volumetric carbonation constant rate, $\mathrm{s}^{-1}$ \\
\hline $\mathrm{k}_{\mathrm{comb}}$ & Volumetric combustion constant rate, $\mathrm{s}^{-1}$ \\
\hline kreac & superficial reaction rate constant, $\mathrm{s}-1$ \\
\hline $\mathrm{N}_{\mathrm{CaO}}$ & Total amount of $\mathrm{CaO}$ moles in the bed, $\mathrm{kmol} / \mathrm{m}^{2}$ \\
\hline $\mathrm{P}$ & Total pressure, atm \\
\hline $\mathrm{P}_{\mathrm{CO} 2}$ & $\mathrm{CO}_{2}$ partial pressure, atm \\
\hline$\overline{\mathrm{P}}_{\mathrm{CO} 2}$ & Mean $\mathrm{CO}_{2}$ partial pressure over the bed, atm \\
\hline $\mathrm{P}_{\mathrm{CO} 2, \mathrm{e}}$ & Equilibrium $\mathrm{CO}_{2}$ partial pressure over $\mathrm{CaO}$, atm \\
\hline $\begin{array}{l}\mathrm{PM}_{\text {calc }} \\
\mathrm{u}\end{array}$ & $\begin{array}{l}\text { Molecular weight of solids at the inlet of combustor-carbonator, } \mathrm{kg} / \mathrm{kmol} \\
\text { Superficial gas velocity, } \mathrm{m} / \mathrm{s}\end{array}$ \\
\hline $\mathrm{X}_{\text {active }}$ & Fraction of active $\mathrm{CaO}$ reacting in the fast reaction regime \\
\hline $\mathrm{X}_{\mathrm{carb}}$ & Solids carbonate content at the exit of the combustor-carbonator \\
\hline $\mathrm{X}_{\max }$ & Maximum carbonation achieve at the final fast reaction regime \\
\hline$\alpha$ & stoichiometric biomass factor \\
\hline & $\begin{array}{l}\text { Solids carbonate content difference between the inlet and outlet of combustor- } \\
\text { carbonator }\end{array}$ \\
\hline & Effectiveness factor \\
\hline
\end{tabular}

\section{References}

(1). Abanades, J.C.; Alonso, M.; Rodriguez, N., Biomass combustion with in situ CO2 capture by $\mathrm{CaO}$. I. Process analysis and economics. Ind. Eng. Chem. Res. 2010,

(2). Werther, J.; Saenger, M.; Hartge, E. U.; Ogada, T.; Siagi, Z., Combustion of agricultural residues. Prog. En. Comb. Sci. 2000, 26, 1

(3). Bridgwater, A. V., The technical and economic feasibility of biomass gasification for power generation. Fuel 1995, 74, 631

(4). van Loo, S.; Koppejan, J. (Eds.), Handbook of Biomass Combustion and Co-Firing. Twente University Press: Enschede, Netherlands, 2004. 
(5). Nussbaumer, T., Combustion and co-combustion of biomass: fundamentals, technologies, and primary measures for emission reduction. Energy Fuels 2003, 17, 1510

(6). Khan, A. A.; de Jong, W.; Jansens, P. J.; Spliethoff, H., Biomass combustion in fluidized bed boilers: Potential problems and remedies. Fuel Process. Technol. 2009, 90, 21 (7). Muthukrishnan, M.; Sundararajan, S.; Viswanathan, G.; Sarajam, S.; Kamalanathan, N.; Ramakrishnan, P. In Salient features and operating experience with world's first rice straw fluidized bed boiler in a $10 \mathrm{MW}$ power plant, 13th International Conference on Fluidized bed Combustion, KJ, H., Ed. Orlando, FL, New York, NY, 1995; ASME: pp 609. (8). Pfeifer, C.; Puchner, B.; Hofbauer, H., In-situ CO2-absorption in a dual fluidized bed biomass steam gasifier to produce a hydrogen rich syngas. International Journal of Chemical Reactor Engineering 2007, 5,

(9). Pfeifer, C.; Puchner, B.; Hofbauer, H., Comparison of dual fluidized bed steam gasification of biomass with and without selective transport of CO2. Chem. Eng. Sci. 2009, 64,5073

(10). Proll, T.; Hofbauer, H., H-2 rich syngas by selective CO2 removal from biomass gasification in a dual fluidized bed system - Process modelling approach. Fuel Process. Technol. 2008, 89, 1207

(11). Florin, N. H.; Harris, A. T., Enhanced hydrogen production from biomass with in situ carbon dioxide capture using calcium oxide sorbents. Chem. Eng. Sci. 2008, 63, 287 (12). Gonzalez, B.; Alonso, M.; Abanades, J.C., Sorbent attrition in a carbonation/calcination pilot plant for capturing $\mathrm{CO} 2$ from flue gases. Fuel 2010, in press, (13). Demirbas, A., Combustion characteristics of different biomass fuels. Prog. En. Comb. Sci. 2004, 30, 219 
(14). Rodriguez, N.; Alonso, M.; Grasa, G.; Abanades, J. C., Heat requirements in a calciner of $\mathrm{CaCO}_{3}$ integrated in a $\mathrm{CO}_{2}$ capture system using $\mathrm{CaO}$. Chem. Eng. J. 2008, 138, 148

(15). Grasa, G. S. ; Abanades, J. C. , $\mathrm{CO}_{2}$ capture capacity of $\mathrm{CaO}$ in long series of carbonation/calcination cycles. Ind. Eng. Chem. Res. 2006, 45, 8846

(16). Abanades Garcia, J. C. ; Alonso, M. ; Rodriguez, N. , Experimental validation of in situ $\mathrm{CO} 2$ capture with $\mathrm{CaO}$ during the low temperature combustion of biomass in a fluidized bed reactor. Int. J. Green. Gas. Cont. 2010, d.o.i 10.1016/j.ijggc 2010.01.006, (17). Leckner, B., Fluidized bed combustion: Mixing and pollutant limitation. Prog. En. Comb. Sci. 1998, 24, 31

(18). Bhatia, S. K.; Perlmutter, D. D. , Effect of the product layer on the kinetics of the $\mathrm{CO}_{2}$-lime reaction. AIChE J. 1983, 29, 79

(19). Grasa, G.; Murillo, R.; Alonso, M.; Abanades, J. C., Application of the Random Pore Model to the Carbonation Cyclic Reaction. AIChE J. 2009, 55, 1246

(20). Abanades, J. C.; Anthony, E. J.; Lu, D. Y.; Salvador, C.; Alvarez, D., Capture of $\mathrm{CO}_{2}$ from combustion gases in a fluidized bed of $\mathrm{CaO}$. AIChE J. 2004, 50, 1614 (21). Alonso, M. ; Rodríguez, N. ; Grasa, G. ; Abanades, J. C., Modelling of a fluidized bed carbonator reactor to capture $\mathrm{CO} 2$ from a combustion flue gas. Chem Eng Sci 2009, 64, 883

(22). Grasa, G. S.; Abanades, J. C.; Alonso, M.; Gonzalez, B., Reactivity of highly cycled particles of $\mathrm{CaO}$ in a carbonation/calcination loop. Chem Eng $J \mathbf{2 0 0 8 ,}$, 137, 561

(23). Gonzalez, B.; Grasa, G. S.; Alonso, M.; Abanades, J. C., Modeling of the Deactivation of $\mathrm{CaO}$ in a Carbonate Loop at High Temperatures of Calcination. Ind. Eng. Chem. Res. 2008, 47, 9256 
(24). Charitos, A. ; Hawthorne, C. ; Bidwe, A. ; He, L. ; Scheffknecht, G. In Design of a dual fluidised bed system for the post combustion removal of $\mathrm{CO} 2$ using $\mathrm{CaO}$. Part II: scaled cold model investigation., 9th International Conference on Circulating Fluidized

Beds, Joachim Werther, W. N., Karl-Ernst Wirth and Ernst-Ulrich Hartge, Ed. Hamburg, Germany, 2008, 753. 


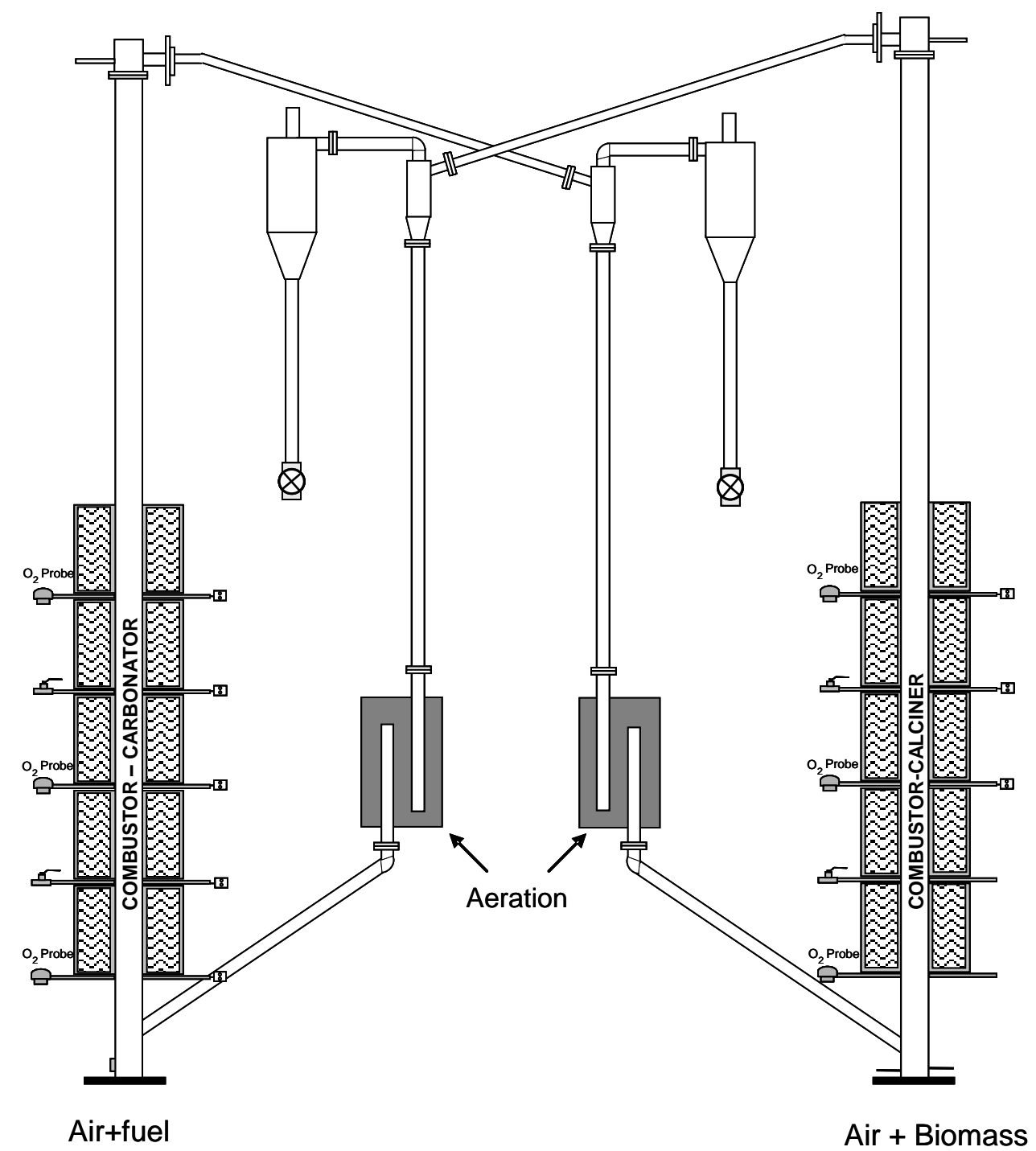

Figure 1. Experimental set-up. 


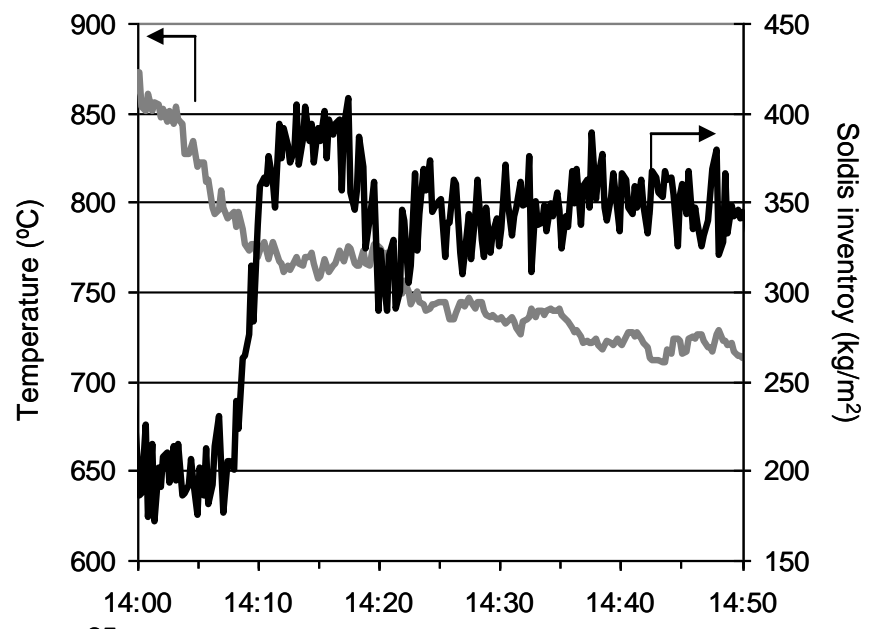

(a)

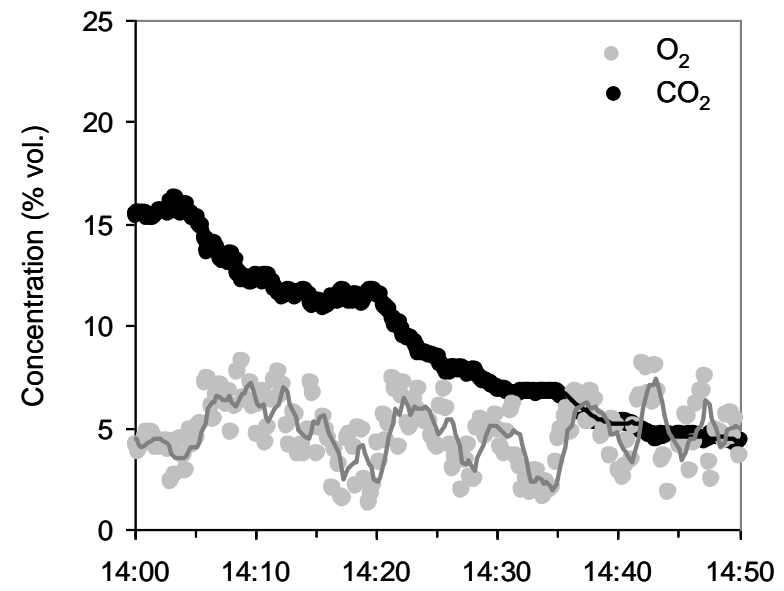

(b)

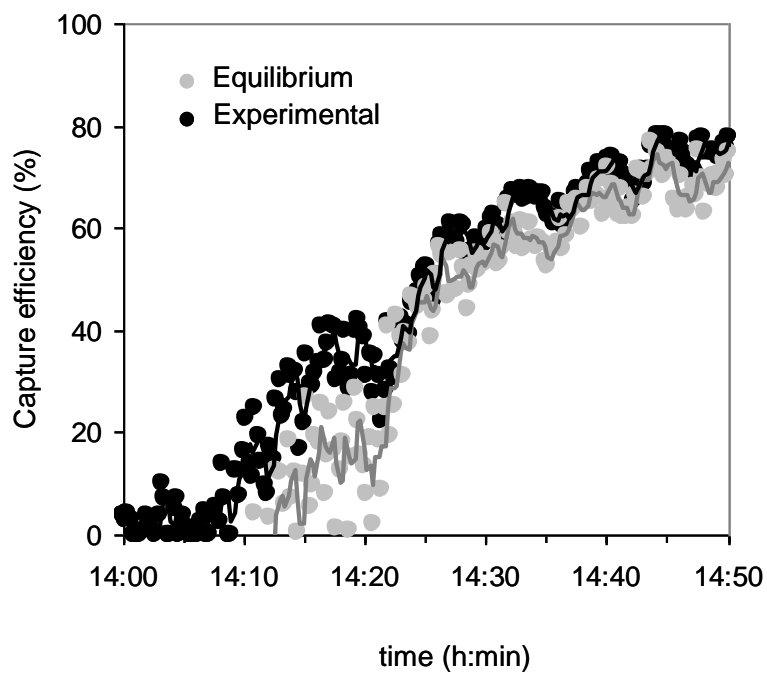

(c)

Figure 2. Start up of combustion with "in situ" $\mathrm{CO}_{2}$ capture. (a) Bed temperature and Solids inventory in the combustor-carbonator. (b) $\mathrm{O}_{2}$ and $\mathrm{CO}_{2}$ concentrations at the exit of primary cyclone of the combustor-carbonator. (c) Experimental $\mathrm{CO}_{2}$ capture efficiency and maximum capture efficiency at equilibrium 


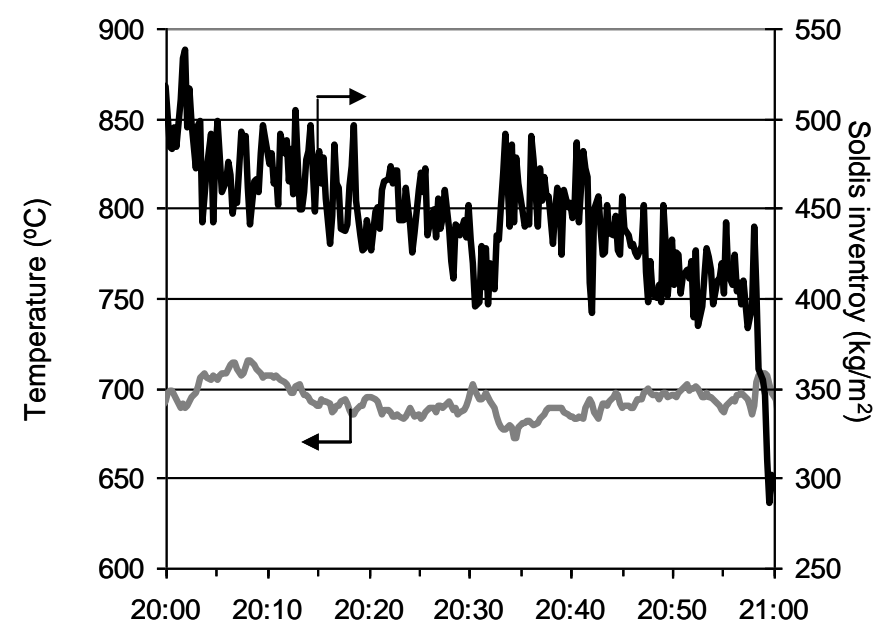

(a)

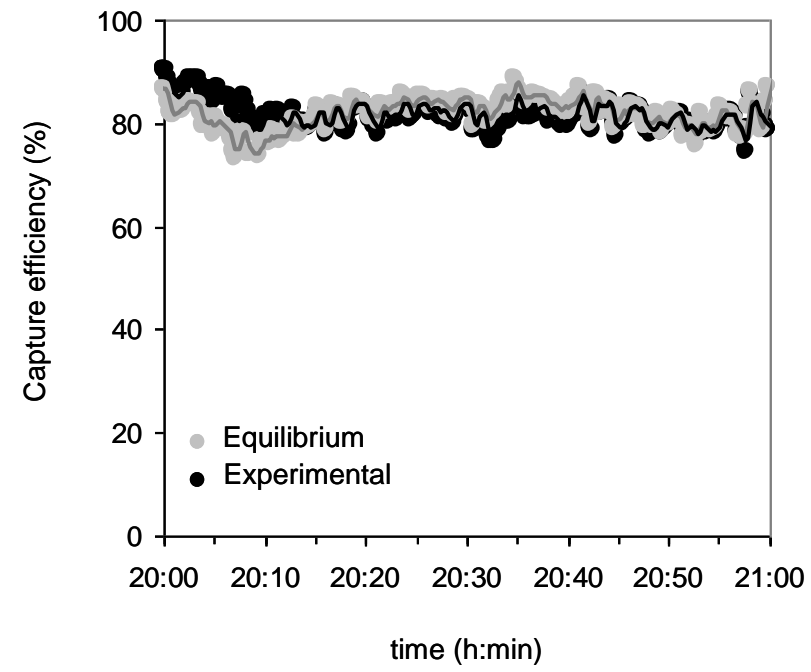

(b)

Figure 3. Combustion with "in situ" $\mathrm{CO}_{2}$ capture at steady-state. (a) Bed temperature and Solids inventory in the combustor-carbonator. (b) Experimental $\mathrm{CO}_{2}$ capture efficiency and maximum capture efficiency at equilibrium 


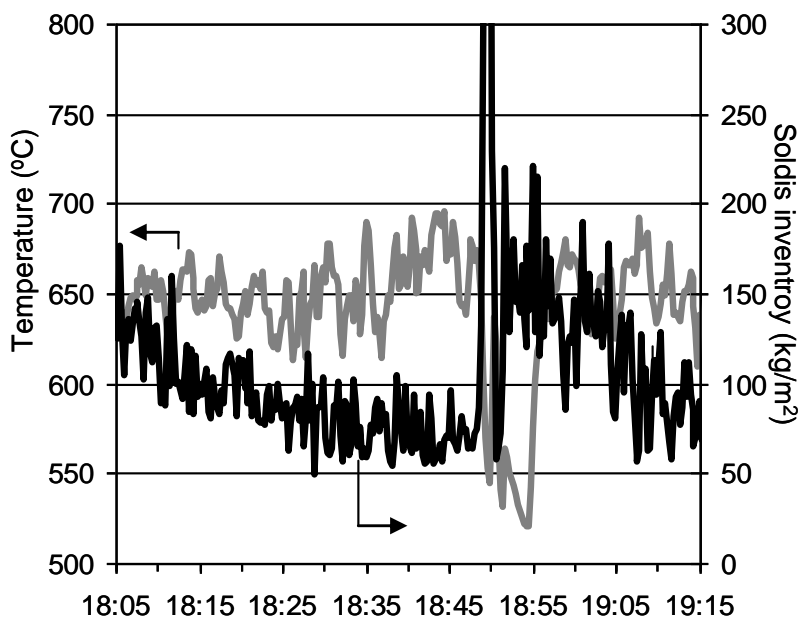

(a)

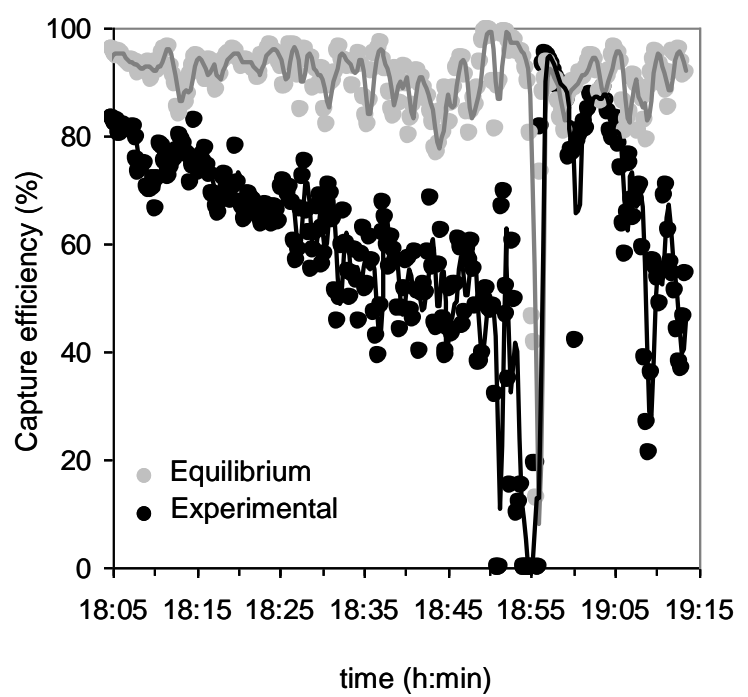

(b)

Figure 4. Combustion with "in situ" $\mathrm{CO}_{2}$ capture when the solids inventory decreases. (a) Bed temperature and Solids inventory in the combustor-carbonator. (b) Experimental $\mathrm{CO}_{2}$ capture efficiency and maximum capture efficiency at equilibrium 


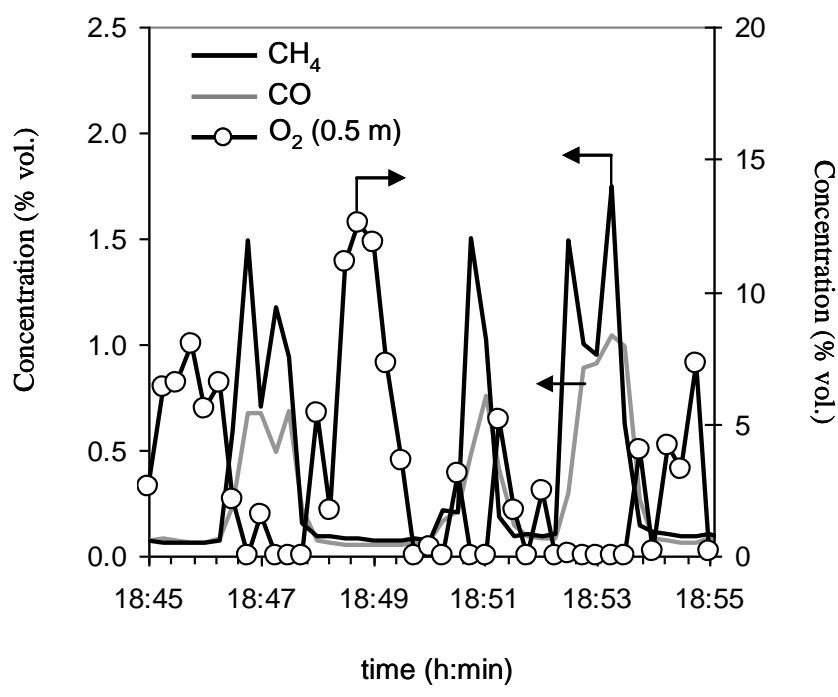

(a)

Figure 5. Gaseous emissions at the exit of the combustor-carbonator. $\mathrm{O}_{2}$ concentration measured by the oxygen zirconia probe located $0.5 \mathrm{~m}$ above the feed point and $\mathrm{CH}_{4}$ and $\mathrm{CO}$ concentrations measured by the on-line gas analyzer at the exit of the primary cyclone of the combustor-carbonator. 


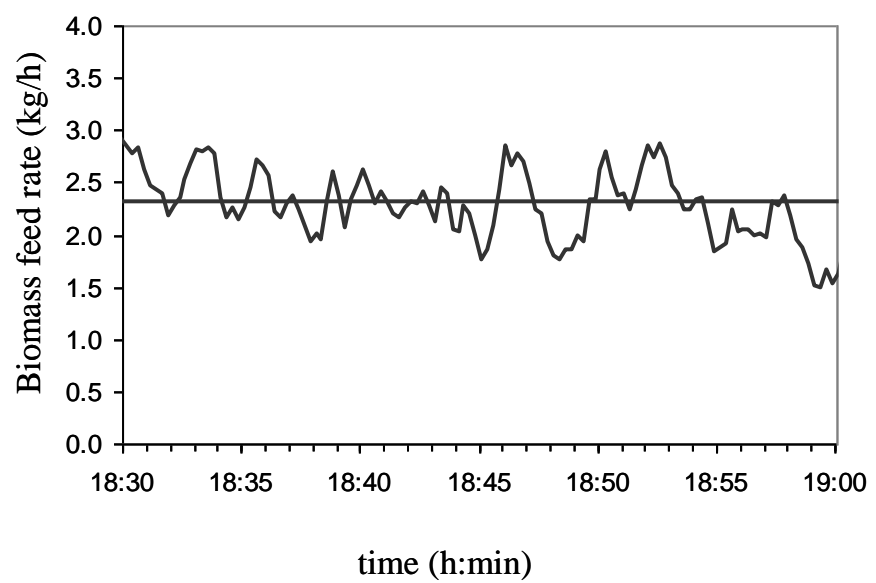

Figure 6. Biomass feed rate measured by the screw feeder (black line) and biomass feed rate estimated by the stoichiometry, the biomass composition and the amount of $\mathrm{O}_{2}$ consumed. 


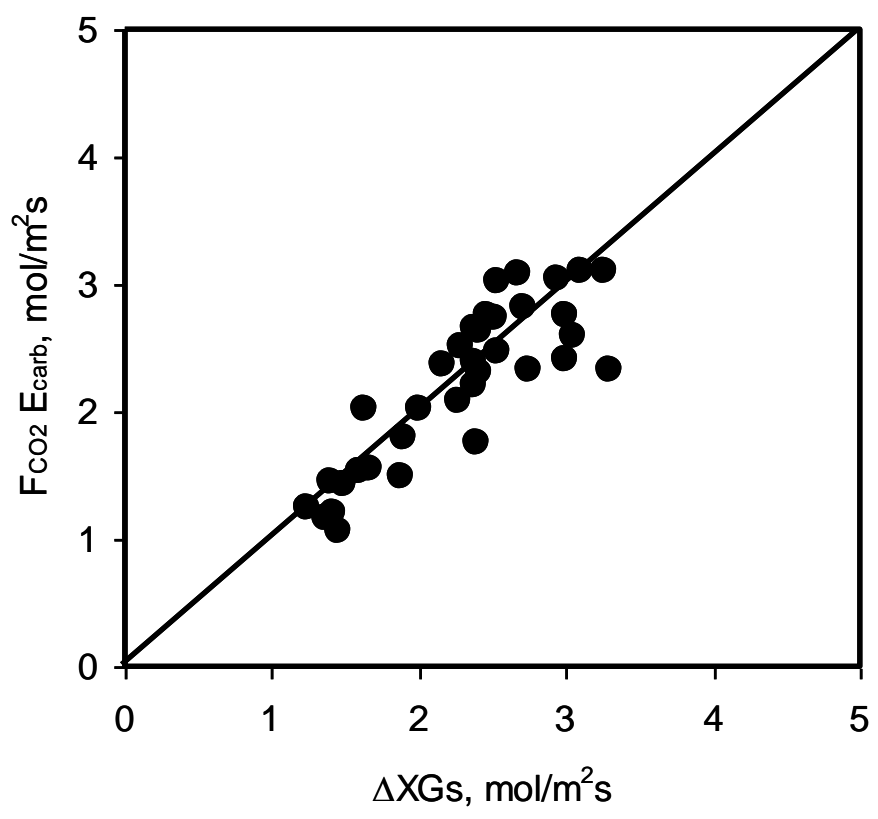

(a)

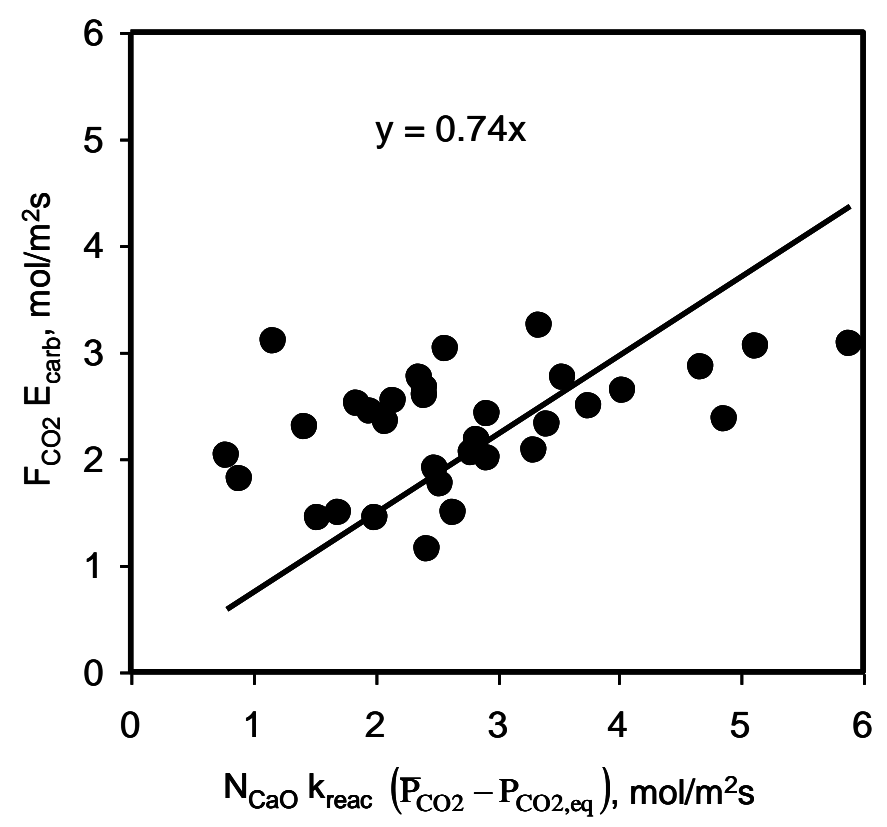

(b)

Figure 7. Closure of the mass balances. (a) $\mathrm{CO}_{2}$ capture molar flow rate measured in the gas phase vs. flow of calcium carbonate circulating between combustor-carbonator and calciner. (b) $\mathrm{CO} 2$ capture molar flow rate measured in the gas phase vs flow of $\mathrm{CO} 2$ reacting with the solids bed inventory in the combustor-carbonator 
Table 1. Analysis of the biomass used (mass basis) (*dry basis)

\begin{tabular}{|c|c|c|c|c|c|c|c|c|c|c|c|}
\hline \multirow[t]{2}{*}{ Fuel } & \multicolumn{4}{|c|}{ Proximate analysis } & \multicolumn{5}{|c|}{ Ultimate analysis* } & \multirow{2}{*}{$\begin{array}{l}\mathrm{LHV} \\
\mathrm{MJ} / \mathrm{kg}\end{array}$} & \multirow{2}{*}{$\begin{array}{l}\mathrm{HHV} \\
\mathrm{MJ} / \mathrm{kg}\end{array}$} \\
\hline & Moisture \% & Volatile $\%$ & $\mathrm{FC}^{\mathrm{a}} \%$ & Ash \% & $\mathrm{C} \%$ & $\mathrm{H} \%$ & $\mathrm{O}^{\mathrm{a}} \%$ & $\mathrm{~N} \%$ & $\mathrm{~S} \%$ & & \\
\hline Saw dust & 6.2 & 83.1 & 8.5 & 2.2 & 48.9 & 6.0 & 42.7 & 0.21 & 0.01 & 15.5 & 16.7 \\
\hline Crushed olive pits & 10.3 & 81.7 & 7.3 & 0.7 & 51.2 & 5.9 & 42.1 & 0.18 & 0.00 & 19.9 & 20.3 \\
\hline Wood pellets & 7.2 & 76.7 & 10.3 & 5.8 & 44.6 & 5.8 & 43.0 & 0.76 & 0.04 & 17.7 & 18.9 \\
\hline
\end{tabular}

\footnotetext{
${ }^{\mathrm{a}}$ by difference
} 
Table 2

Bed Temperature $\left({ }^{\circ} \mathrm{C}\right)$

610-720

Superficial gas velocity at the inlet $(\mathrm{m} / \mathrm{s})$

$1.5-2.4$

$v \mathrm{CO}_{2}$ combustion (\%)

7.3-15.9

Solids circulation flow rate $\left(\mathrm{kg} / \mathrm{m}^{2} \mathrm{~s}\right)$

0.6-3.5

Bed inventory $\left(\mathrm{kg} / \mathrm{m}^{2}\right)$

45-650 